\title{
Modelos de carteiras escolares propostos pela Direção-Geral de Instrução Pública de Portugal (1877): a referência da Exposição Universal de Viena
}

\section{School desks models proposed by the General Direction of Public Instruction of Portugal (1877): the reference of The Vienna Universal Exhibition}

\author{
Carlos Manique da Silva*
}

\begin{abstract}
RESUMO
No presente artigo admite-se que a cultura material constitui uma fonte essencial para conhecer o passado da escola. A essa luz, são analisados diversos modelos de carteiras escolares propostos pela Direção-Geral de Instrução Pública de Portugal, no ano de 1877. Uma das ideias defendidas é a de que a difusão dos mencionados modelos é legitimada na referência à experiência estrangeira, nomeadamente, a um modelo de carteira escolar (sistema de Kunze) apresentado na Exposição Universal de Viena de Áustria (1873). Sendo a carteira escolar um dos expoentes do processo de oficialização do aluno, aquilo que se observa, no contexto de acolhimento, é que é mínima a permeabilidade ao conhecimento veiculado (isto é, ao modelo exterior). Por outras palavras, a nível local, observa-se resistência à classificação e estandardização criadas pelas exposições universais; expressão, entre outras, de uma determinada realidade pedagógica.
\end{abstract}

Palavras-chave: Carteira escolar. Cultura material. Exposições universais. Conhecimento pedagógico. Portugal.

* Universidade de Lisboa. Instituto de Educação. Email: manique@net.sapo.pt. https://orcid. org/0000-0003-4210-0723. 


\begin{abstract}
In the present article it is admitted that the material culture constitutes an essential source to get to know the past of schools. According to this view, several models of school desks proposed by the General Direction of Public Instruction of Portugal in the year of 1877 are analyzed. One of the defended ideas is that the diffusion of the mentioned models is legitimized in the reference to the foreign experience, namely, to a model of school desk (system of Kunze) presented in the Universal Exhibition of Vienna of Austria (1873). Since the school desk is one of the exponents of the student's officialisation process, what is observed in the host context is that the permeability to the conveyed knowledge (e.g., the external model) is minimal. In other words, a resistance to the classification and standardization created by universal exhibitions is observed at local level; expression, among others, of a certain pedagogical reality.
\end{abstract}

Keywords: School desk. Material culture. Universal Exhibitions. Pedagogical knowledge. Portugal.

\title{
Introdução
}

Na segunda metade do século XIX, as exposições universais estabelecem entre as nações emergentes uma hierarquia de progresso e modernidade. Há um sentido de idealização e de visão de futuro que passa, por exemplo, pela valorização da cultura transmitida pelo sistema de ensino - do que se trata é da transversalidade da escola enquanto minissistema social destinado a preparar o cidadão. Ora, as exposições universais têm um papel relevante na divulgação de uma certa forma de escolarização. Para o efeito, basta pensar nos objetos expostos nesses certames: projetos-tipo de edifícios escolares, modelos de carteiras, coleções de instrumentos científicos, quadros parietais, manuais escolares, entre outros. Estamos a falar de objetos que em determinado momento histórico foram inovações, passando (por vezes, muito rapidamente) a "modernidades abandonadas", para adotar a expressão de Martin Lawn. Interessa, pois, distinguir a conceção, o ciclo de uso e, obviamente, o pós-uso dos objetos (OLSON; REILLY; SHEPHERD, 2006).

No presente texto darei especial atenção à cultura material da escola, no sentido que lhe atribui Agustín Escolano (2009, p. 32); ou seja, enquanto parte integrante da cultura empírica das instituições educacionais - "the visible exponent"1.

1 "O expoente visível". 
Admitindo que a cultura material constitui uma fonte essencial para compreender o passado da escola, procuro analisar diversos projetos (modelos) de carteiras escolares (ensino primário e ensino normal) propostos pela Direção-Geral de Instrução Pública de Portugal no ano de 1877, os quais são "legitimados" na referência à experiência estrangeira. Refiro-me especificamente a um modelo de carteira escolar divulgado na Exposição Universal de Viena de Áustria (1873). Aquilo que me interessa, tendo em conta que o projeto escolar lançado no século XIX é um projeto de normalização (dos edifícios e carteiras escolares, da didática, do currículo, da utilização do quadro preto...), é perceber de que forma o conhecimento pedagógico circula e é apropriado - conhecimento que é "socialmente construído no âmbito de "redes de comunicação"” (CARVALHO, 2009, p. 190). Mais explicitamente, focar-me-ei na fase de desenho. De que modo é "internalizado" - o termo deve ser lido no sentido atribuído por David Phillips (2004) - o modelo de carteira escolar estrangeiro? Em outras palavras, no contexto de acolhimento, qual é a permeabilidade ao conhecimento que é veiculado? Questões que remetem para o meu posicionamento teórico, cuja filiação se reconhece nas palavras de Mary Morgan (2011, p. 7): "in travelling to other spheres [...] we found that facts [knowledge] may grow in scope, sharpen or become more rounded; they may acquire new labels and fulfil new functions, even while they maintain a strong hold on their integrity"2.

\section{A Exposição Universal de Viena de Áustria (1873): importância atribuída ao mobiliário escolar e participação portuguesa}

Portugal esteve representado nas exposições universais desde o início desses certames (Londres, 1851) e teve, aliás, algum pioneirismo na organização de exposições industriais (de caráter nacional) no tempo do Marquês de Pombal (SOUTO, 2011).

A minha atenção focar-se-á em especial na presença de Portugal na Exposição Universal de Viena de Áustria (1873), no essencial, por duas ordens de razões. Desde logo, por se tratar da primeira exposição universal em que o

2 "Ao viajar para outras esferas descobrimos que os factos [conhecimento] podem alargar a sua extensão, aguçar-se ou tornar-se mais abrangentes; podem adquirir novos rótulos e preencher novas funções, mesmo quando mantêm uma forte ligação à sua integridade." 
trinómio "educação, ensino, instrução" é manifestamente assumido 3 . Por outro lado, pelo facto de algumas ideias pedagógicas nela apresentadas terem influenciado a política educativa portuguesa. Penso, em particular, na divulgação pela Direção-Geral de Instrução Pública (1877) de mobiliário escolar normalizado, tendo por referência um modelo de carteira escolar difundido nessa Exposição. Outra questão, obviamente, é a de saber até que ponto essa influência contribuiu diretamente para uma mudança real. A própria análise da participação portuguesa na referida Exposição ajudar-nos-á a compreender esta última asserção.

Antes, porém, de proceder a essa análise, um dos aspetos que importa abordar prende-se com a importância que o mobiliário escolar assume no certame de Viena (integrando a secção "Ensino"). Se, em 1867, na Exposição Universal de Paris, havia sido posta a questão da reforma do mobiliário escolar, assinalando-se os efeitos negativos sobre a saúde dos alunos (SILVA, 2002), em Viena, por sua vez, é sistematizado (em função de novos avanços científicos nos campos médico e pedagógico) um conjunto de regras para a construção de mobiliário escolar. O princípio de partida, segundo Buisson (1875, p. 55), foi o seguinte: "le banc doit s'accommoder à l'enfant et non plus l'enfant au banc"4. A este respeito, ainda, Buisson deixa clara a ideia de as exposições universais serem o espaço destinado a mostrar o que de mais atual e superior era pensado e produzido:

Il ne sera peut-être pas inutile de résumer ici brièvement l'historique de cette question [le mobilier scolaire]. L'Exposition de Vienne offrait, pour l'étudier, un ensemble assez riche des documents et de spécimens, dont quelques-uns étaient tout récents. En les examinent, on pouvait suivre presque d'année en année les améliorations graduellement introduites dans le mobilier scolaire (BUISSON, 1875, p. 51).

Ferdinand Buisson, no relatório que tenho vindo a citar, elenca os mais importantes sistemas de mobiliário escolar apresentados na Exposição de Viena;

3 Deve referir-se que a Exposição Universal de Londres, de 1862, foi a primeira a consagrar uma secção unicamente dedicada ao ensino; a qual receberá especial atenção na Exposição Universal de Paris, de 1867 (BUISSON, 1875).

4 "O banco deve acomodar-se à criança e não a criança ao banco."

5 "Não será talvez inútil resumir aqui sucintamente a história desta questão [o mobiliário escolar]. A Exposição de Viena oferecia, para o estudar, um conjunto bastante rico de documentos e de exemplares, entre os quais, alguns muito recentes. Ao examiná-los podíamos seguir quase de ano a ano os melhoramentos gradualmente introduzidos no mobiliário escolar." 
percebe-se que, nesse momento histórico, existe já um mercado de construtores especializados. Um dos sistemas que Buisson destaca é o de Kunze, construído pela fábrica alemã Bahse e Haendel (em Viena recebeu a medalha de progresso) e adotado pelo Ministério da Instrução Pública de Saxe. Além de ser o mais difundido na Alemanha e na Áustria, o sistema de Kunze, segundo crê Buisson, também era utilizado na Rússia. Teve, aliás, bastantes "imitações”. A verdade, constatá-la-emos a seu tempo, é que, em Portugal, a Direção-Geral de Instrução Pública (1877) proporá diversos modelos de carteiras escolares referenciando o modelo de Kunze.

Por outro lado, importa perceber que consequências resultaram da participação direta de Portugal na Exposição Universal de 1873. À partida, foi notória a vontade de o país se fazer representar de forma condigna, algo que fica patente na personalidade nomeada para comissariar a presença portuguesa. Falo de Joaquim Henriques Fradesso da Silveira (1825-1875). Jornalista, professor da Escola Politécnica, diretor do Observatório Meteorológico de Lisboa, promotor do desenvolvimento industrial do país, tendo, também, desempenhado cargos políticos (deputado, por exemplo), viria a revelar-se um comissário infatigável (SOUTO, 2011) ${ }^{6}$. Os dois documentos oficiais que publicou relativamente à Exposição dão bem conta da sua ação. No espírito do comissário régio perpassava a ideia de Portugal se poder afirmar a par de países considerados desenvolvidos. Refere Fradesso da Silveira, transcrevendo um diploma oficial, que se defendia a

necessidade e conveniência que Portugal se faça representar naquele grande concurso internacional de modo [a] que possa quinhoar o apreço e galardão a que tem direito um povo que se esforça por melhorar as condições da sua vida literária, moral e científica" (FRADESSO DA SILVEIRA, 1874, p. 64).

Para o efeito, no âmbito dos trabalhos preparatórios para a Exposição, foram convidados os estabelecimentos de ensino superior a escolher "os objetos mais próprios a mostrar o estado e progressos do ensino", os liceus a serem

6 No âmbito da Exposição de Viena, o comissário Fradesso da Silveira foi agraciado pelas autoridades austríacas e portuguesas. Na verdade, a representação portuguesa esteve muito alicerçada nessa personalidade. Fradesso da Silveira queixou-se, de resto, da falta de resultados dos colaboradores nomeados (SOUTO, 2011). Entre outras valências, a figura em causa desempenhou também importante papel na difusão de instrumentos de registo fotográfico (PERES; COSTA; JARDIM, 2014). 
representados "por meio de fotografias ou plantas dos edifícios públicos em que funcionarem [...], estatísticas, horários, compêndios, catálogos, trabalhos dos alunos [...]”, assim como os governadores civis, em articulação com os comissários dos estudos, seriam encarregados de "promover a exposição de objetos pertencentes à instrução primária" (FRADESSO DA SILVEIRA, 1874, p. 65-66).

Aquilo que se pode dizer é que o comissário Fradesso da Silveira pautou a sua intervenção pela economia de custos. Com efeito, e ao contrário do sucedido na Exposição Universal de 1867, onde muitos países optaram por apresentar modelos de arquiteturas nacionais para os seus pavilhões (SOUTO, 2011), em Viena, Portugal - à semelhança, aliás, dos Estados Unidos da América e da Suécia -, preferiu construir um edifício de escola primária (pré-fabricado). Porém, no caso português, tratava-se, inequivocamente, de uma política de contenção de despesas, uma vez que tal edifício, a par de acolher a exposição de trabalhos escolares e de objetos didáticos, serviu para acomodar (no piso superior) o pessoal da representação portuguesa (FRADESSO DA SILVEIRA, 1874).

FIGURA 1 - MODELO DE ESCOLA PRIMÁRIA PORTUGUESA APRESENTADO NA EXPOSIÇÃO UNIVERSAL DE VIENA DE ÁUSTRIA (1873)

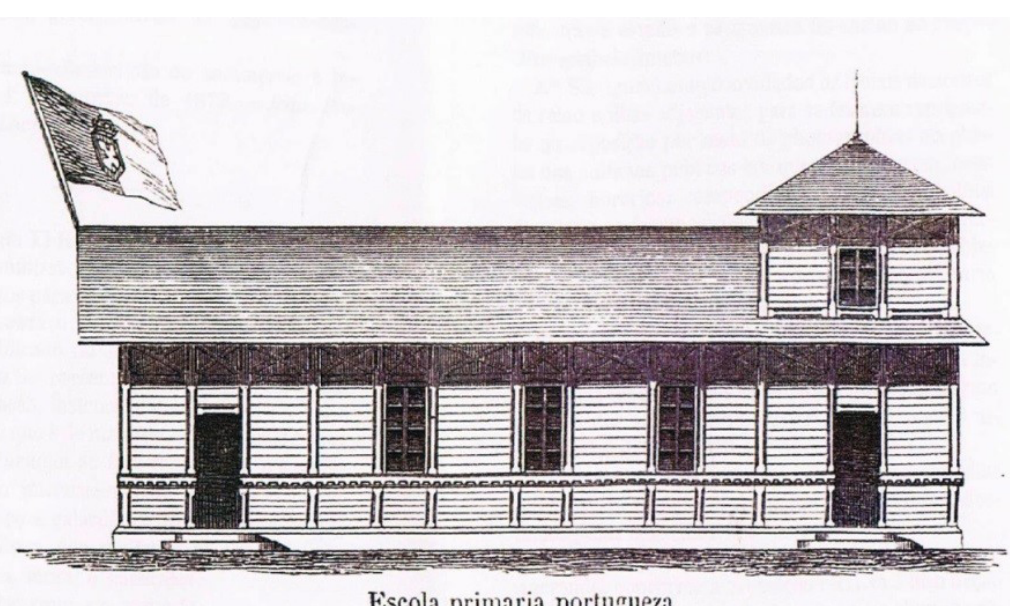

Escola primaria portugueza

FONTE: Fradesso da Silveira, 1874. 
Não obstante a referida situação, Portugal recebeu alguns diplomas de mérito no grupo "educação, ensino, instrução", atribuídos, nomeadamente, à Associação Protetora de Meninas Pobres, ao Asilo D. Pedro V, à Escola Normal de Lisboa, assim como ao Ministério do Reino (FRADESSO DA SILVEIRA, 1873). Neste último caso, a menção foi conferida ao modelo de escola primária reproduzido na Figura 1.

Interessante é confrontar essa perspetiva (a de reconhecimento de mérito) com o olhar apurado e crítico de Ferdinand Buisson:

À l'ouverture de l'exposition, trois écoles étaient construites ou en construction : l'école portugaise, l'école suédoise et celle des États-Unis.

La première n'offrait aucun détail caractéristique sur le mode d'installation, ni même sur les particularités d'appropriation qui doit exiger le climat du midi ; elle ne contenait, outre le vestibule, qu'une grande salle garnie de quelques meubles de classe très-imparfaites. Il était difficile de s'expliquer le but qu'on avait pu se proposer en élevant cet édifice peu remarquable (BUISSON, 1875, p. 14)7.

Por outro lado, Buisson, mantendo referências pouco elogiosas à participação portuguesa, introduz (dir-se-ia, sem surpresa) a seguinte clivagem/ comparação entre países:

Ce même caractère, sérieux et simple, se retrouvait à divers degrés dans les écoles suédoises, dans quelques écoles autrichiennes et suisses. Au contraire, quelques autres pays, le Portugal et l'Espagne par exemple, n'exposaient qui des ouvrages de parade, quelques-uns d'un goût douteux (BUISSON, 1875, p. 143)

7 "Aquando da abertura da exposição, três escolas estavam construídas ou em construção: a escola portuguesa, a escola sueca e a dos Estados Unidos. A primeira não oferecia nenhum detalhe caraterístico acerca do modo de instalação, nem mesmo sobre as particularidades de adaptação que deve exigir um clima do sul; ela não continha, a não ser o vestíbulo, uma grande sala guarnecida com alguns móveis de sala de aula muito imperfeitos. Era difícil de se explicar o objetivo que se havia proposto ao construir este edifício pouco notável."

8 "Este mesmo caráter, sério e simples, encontrava-se em diversos graus nas escolas suecas, em algumas escolas austríacas e suíças. Por outro lado, alguns países, como Portugal e Espanha, por exemplo, não expuseram senão obras de fachada, algumas de gosto duvidoso." 
Na segunda metade do século XIX, as exposições universais têm influência no desenvolvimento dos sistemas educativos - sobretudo pela idealização de futuro que projetam. Mas é evidente que esse sentido, de per si, particularmente no caso de um país como Portugal (com um atraso educacional considerável), não se traduz num ganho significativo. Para o efeito, basta pensar nas péssimas condições dos edifícios e mobiliário escolares, evidenciadas, de resto, em numerosos documentos oficiais e na própria imprensa de educação e ensino (inclusivamente, durante a primeira metade do século XX). Seja como for, aquilo que interessa frisar, na linha do pensamento de Martin Lawn (2009, p. 9), é o seguinte: "educational reformers built their innovations around the modernist advances of the exhibitons" ${ }^{9}$. E é, justamente, essa ideia que, em 1877, motivou a Direção-Geral de Instrução Pública a difundir vários modelos de carteiras.

\section{A difusão de modelos de carteiras escolares pela Direção-Geral de Instrução Pública (1877)}

Conforme se disse, em 1877 a Direção-Geral de Instrução Pública ${ }^{10}$ propõe (oficialmente) uma série de projetos (modelos) de carteiras escolares para os ensinos primário e normal. Para modelo de referência, já o explicitarei, toma-se como fonte desenhos (e não, portanto, a observação direta de modelos); relembre-se que, nesse momento histórico, em alguns países da Europa existe já um mercado de construtores especializados, promovendo e comercializando mobiliário escolar apresentado nas exposições universais.

Para a minha agenda de investigação, aquilo que importa não é apenas perceber a filiação dos projetos (modelos) de carteiras escolares. Na verdade, interessa também avaliar que sentido de modernidade a Direção-Geral de Instrução Pública imprime à sua ação (por exemplo, se está perfeitamente alinhada com o que era preconizado em matéria de mobiliário escolar) e, mesmo, em que medida reinterpreta outras soluções.

Julgo útil enfatizar que a carteira escolar representa um dos expoentes máximos do processo de oficialização do aluno. Nesse sentido, não surpreende

9 "Os reformadores educacionais construíram as suas inovações em torno dos avanços modernistas das exposições."

10 Importa dizer que a Direção-Geral de Instrução Pública fora criada por Fontes Pereira de Melo, em 1859, à data ministro dos Negócios do Reino, traduzindo a progressiva especialização do sistema de ensino. 
que em meados da década de 1860 - quando em Portugal se tornam mais visíveis as medidas destinadas a alargar a frequência do ensino - seja publicada legislação muito específica sobre mobiliário escolar ${ }^{11}$, flexibilizada poucos anos mais tarde, precisamente em 1871, pelo facto de a anterior legislação ter sido considerada inexequível dadas as condições materiais da esmagadora maioria das escolas primárias do país (e, também, a ausência de recursos financeiros).

Antes de analisar os projetos (modelos) propostos pela Direção-Geral de Instrução Pública, convém, certamente, ilustrar as principais questões/tendências no respeitante à conceção da carteira escolar nos anos de 1870. Darei essa perspetiva, de forma necessariamente resumida, a partir de uma obra já aqui citada. Falo do relatório de Ferdinand Buisson sobre a instrução primária na Exposição Universal de Viena. Diz-nos Buisson (1875) que, por razões de natureza pedagógica e higienista, a questão capital se prende com a distância entre o banco e a carteira. Surgem, em consequência, dois sistemas: o banco de distância fixa e o banco de distância variável. No primeiro caso, os princípios higienistas sobrepõem-se aos princípios pedagógicos. De facto, em causa está, sobretudo, a preocupação com a postura corporal dos alunos (ponto de vista médico); nesse caso, a distância entre o banco e a carteira é mínima (nula, para adotar o termo técnico referido por Buisson), não permitindo que o aluno possa permanecer em pé. Por outro lado, o banco de distância variável garante que o aluno tenha uma postura correta quando está sentado (por exemplo, a escrever), ao mesmo tempo que permite mobilidade suficiente em outras situações (multifuncional); nomeadamente, de natureza pedagógica (recitações, atividades de canto...).

Há, depois, outros princípios que presidem à conceção do mobiliário escolar na década de 1870 - de algum modo consensuais, segundo expressa Buisson (1875). Refiro-me, em primeiro lugar, à definição da posição do aluno (e, necessariamente, à conformação do mobiliário escolar) no momento em que está sentado; e deve ser esta posição de modo que as pernas formem com as coxas um ângulo reto e que, por sua vez, as coxas definam com o tronco também um ângulo reto (BUISSON, 1875). Um segundo princípio prende-se com a preocupação de o aluno (mantendo a indicada posição do membros inferiores) poder escrever sem forçar a sua posição; isto é, sem dobrar o tronco ou encolher os ombros (BUISSON, 1875). O respeito pelo primeiro princípio implica, obrigatoriamente, a existência (em cada classe) de carteiras escolares com diversas dimensões; adaptadas, pois, às diferentes alturas dos alunos. Na segunda situação, o que está em causa é a relação entre as medidas do banco e da carteira. 
Ferdinand Buisson (1875) fala, ainda, de outros aspetos tidos em consideração no desenho das carteiras escolares. Por exemplo, revela não ser consensual a utilização de suporte para apoio dos pés. Pelo contrário, é unanimemente aceite que o banco deve ter apoio para a região lombar. No mesmo sentido, se define que o tampo da carteira deve ter uma inclinação (variando entre os 15 e os 20 graus).

A síntese apresentada permite olhar agora com outro conhecimento para os modelos de carteiras escolares difundidos pela Direção-Geral de Instrução Pública. Talvez seja útil dizer que, na Exposição de Viena de Áustria (1873), Portugal apresentou um modelo de carteira escolar segundo o sistema de banco de distância fixa (BUISSON, 1875). Por seu turno, em 1877, como notou Maria de Fátima Machado (2004), os modelos apresentados pela Direção-Geral de Instrução Pública tinham caraterísticas bem distintas entre si, uma vez que procuravam dar resposta a diversas situações. Tratava-se, na verdade, de um conjunto de plantas e alçados correspondendo a seis modelos - um deles, ao qual já aludi, referencial e traduzindo a necessidade de olhar a experiência estrangeira, fora criado por Ernest Kunze e apresentado na Exposição Universal de Viena $(1873)^{12}$. Numa primeira leitura, o que se pode dizer? Desde logo, que são propostos modelos segundo os dois sistemas indicados (banco de distância fixa e banco de distância variável). Por outro lado, e em consonância com o que era aceite como regra, a generalidade dos modelos de carteiras escolares não possuía mais de quatro lugares. De facto, nesse momento histórico é reconhecido que "il y a toute sorte d'avantages pédagogiques à renoncer aux anciens modèles de six, huit ou dix places" (BUISSON, 1875, p. 65) ${ }^{13}$. Apenas um dos exemplos, concebido "para as escolas mais simples", contemplava seis a oito lugares.

12 Interessa dizer que um dos modelos se destinava ao ensino normal. Julgo que os modelos em causa nunca passaram da fase de desenho.

13 "Que existe toda a espécie de vantagens pedagógicas em renunciar aos antigos modelos de seis, oito ou dez lugares." 
FIGURA 2 - MODELO DE CARTEIRA ESCOLAR PROPOSTO PELA DIREÇÃOGERAL DE INSTRUÇÃO PÚBLICA (1877)
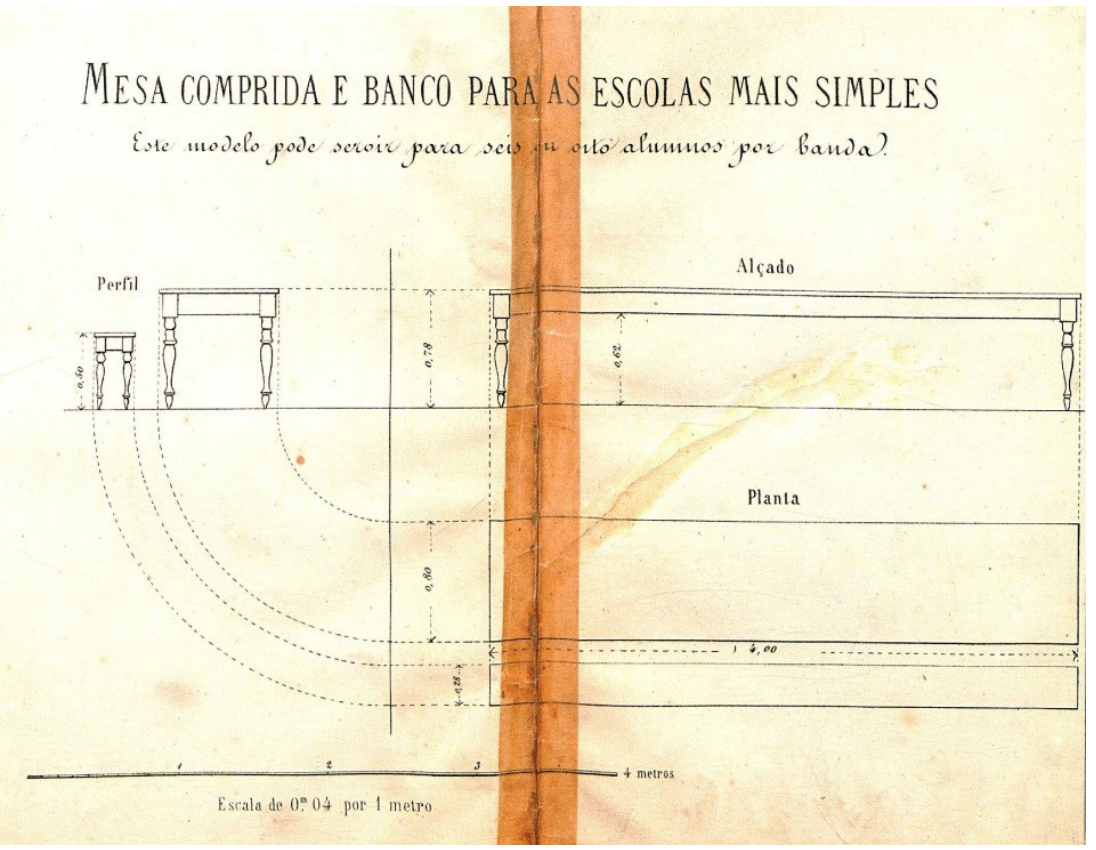

FONTE: Modelos de Mobilia para Instrucção Primaria Organisados pela Direção Geral de Instrucção Publica. Lisboa: Imprensa Nacional, 1877.

No caso em análise, fatores de natureza financeira (e estamos apenas a considerar a fase de desenho, se se preferir, do conceito) ter-se-ão sobreposto a questões pedagógicas e, mesmo, higienistas. Parece, na verdade, não haver qualquer integração da investigação desenvolvida nos anos de 1860-1870 (sobretudo no campo médico) e aplicada à conceção de mobiliário escolar. Veja-se, por exemplo, a proposta de banco: corrido e sem qualquer apoio para a zona lombar; ou a ausência de inclinação do tampo da carteira. No entanto, outras razões poderão ter estado na origem da conceção do referido modelo. Efetivamente, segundo relatam Herman, Van Gorp, Simon e Depaepe (2011), por volta de 1900, nas escolas de Bruxelas, o banco corrido (concebido em 1868) era ainda bastante utilizado, não obstante haver à data dois novos modelos de carteira escolar. Surpreendentemente, aliás, o dito modelo figurou na Exposição Internacional de Bruxelas (1897). Na interpretação dos citados autores, quer isso significar que o mobiliário escolar 
evoluiu mais lentamente do que aquilo que poderia fazer supor a intensa atividade projetista. E adiantam que os modelos que se impuseram foram os que apresentavam similitudes com os "antigos", "which had already demonstrated their suitability and reliability" (HERMAN; VAN GORP; SIMON; DEPAEPE, 2011, p. 116) ${ }^{14}$. Uma ideia à qual regressarei.

Retomando a análise dos modelos de carteira escolar difundidos pela DireçãoGeral de Instrução Pública, importa dizer que o modelo de Kunze - que integrava os dados mais recentes da investigação (sobretudo, médica) - contrastava com os demais. De facto, era projetado de modo a otimizar o conforto e o desempenho do aluno. Por exemplo, o banco (destinado a dois alunos) previa apoio na zona dos rins e das omoplatas. Por outro lado, entre vários requisitos, o tampo da carteira tinha uma inclinação de 20 graus e era móvel, de modo a poder ser levantado e a assegurar espaço para arrumar livros e utensílios. Além do mais, o modelo estava dimensionado em função de oito "alturas".

\section{FIGURA 3 - MODELO DE CARTEIRA ESCOLAR PROPOSTO PELA DIREÇÃO- GERAL DE INSTRUÇÃO PÚBLICA (1877)}

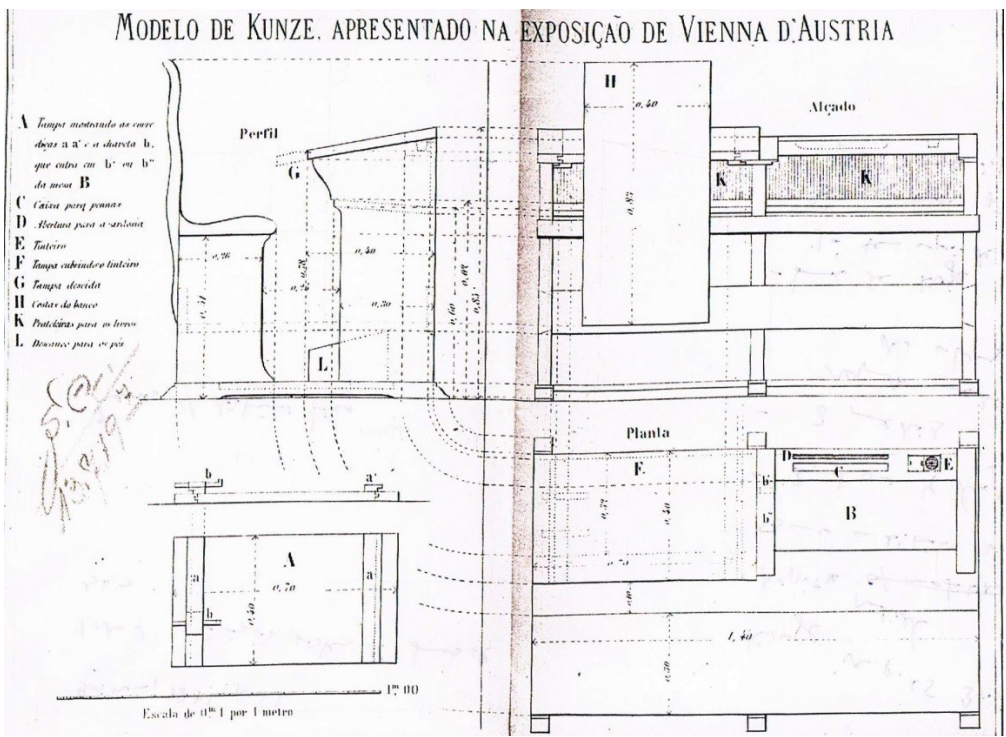

FONTE: Modelos de Mobilia para Instrucção Primaria Organisados pela Direção Geral de Instrucção Publica. Lisboa: Imprensa Nacional, 1877.

14 "Os quais já demonstraram a sua adaptabilidade e fiabilidade". 
Note-se que o modelo de Kunze, divulgado pela Direção-Geral de Instrução Pública, seguia de perto a proposta original e não as versões modificadas do mesmo (algumas delas, de resto, apresentadas na Exposição Universal de Viena).

FIGURA 4 - MODELO DE KUNZE (PROPOSTA ORIGINAL)

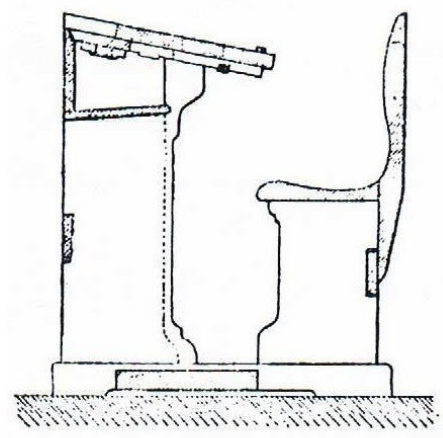

Fig. 14. - Coupe du système hiunze.

FONTE: Buisson (1875).

Quando se têm em conta as caraterísticas e a ergonomia do modelo de Kunze e se considera o conjunto dos outros cinco modelos, do mesmo modo difundidos pela Direção-Geral de Instrução Pública, emerge a ideia que, no contexto de acolhimento, é mínima a integração de conhecimento. Por outras palavras, e já o constatámos aquando da análise do modelo reproduzido na Figura 2, estamos perante conceções de carteira escolar formalmente distintas. O que terá então levado a Direção-Geral de Instrução Pública a difundir o modelo de Kunze? Estou em crer que a razão se prende, sobretudo, com a necessidade de "legitimar" (na referência à experiência estrangeira e ao que de mais avançado se produzia) o conjunto da proposta. Não obstante essa referência, a verdade é que os demais modelos de carteira escolar se afastam da classificação e estandardização criadas pelas exposições universais (LAWN, 2009). Atente-se nos seguintes dados. Os referidos cinco modelos não foram desenhados pensando nas diferentes dimensões dos alunos. Por outro lado, é comum a adoção de banco sem costas. Mas não é um dado adquirido a vantagem (pedagógica e higienista) do tampo inclinado. 
FIGURA 5 - MODELO DE CARTEIRA ESCOLAR PROPOSTO PELA DIREÇÃOGERAL DE INSTRUÇÃO PÚBLICA (1877)

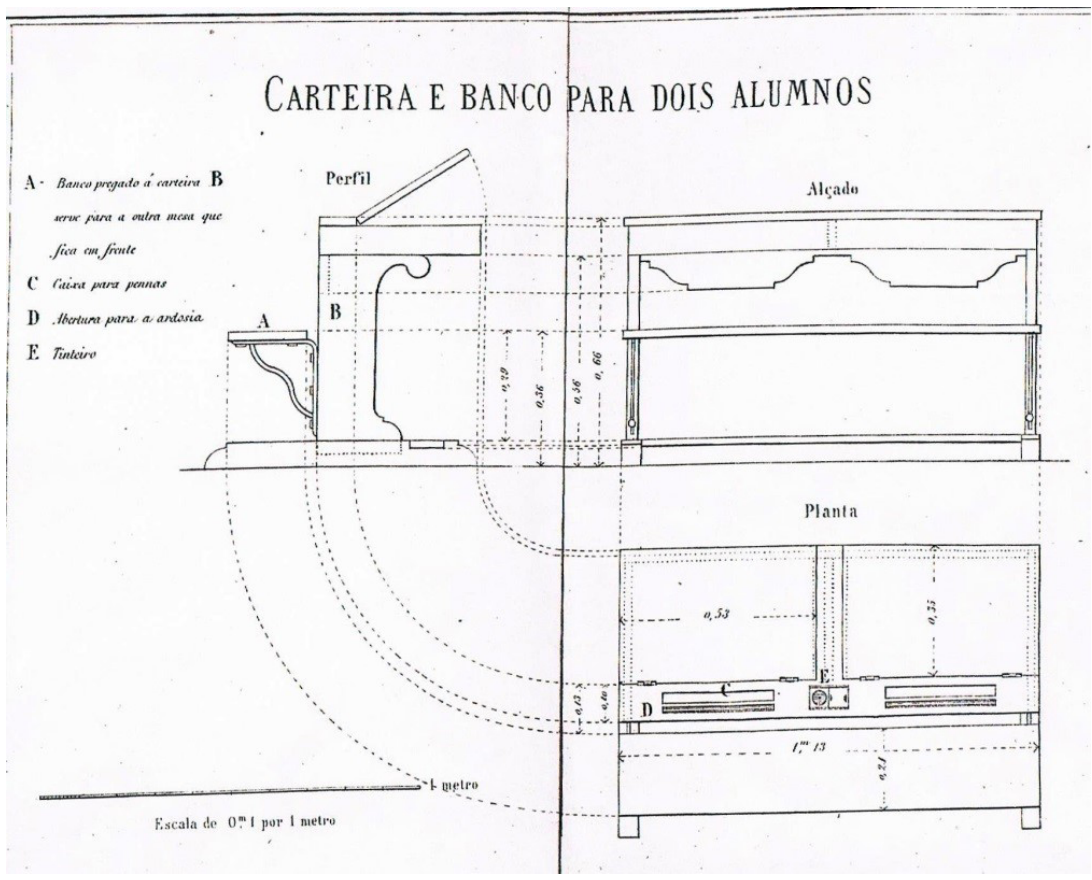

FONTE: Modelos de Mobilia para Instrucção Primaria Organisados pela Direção Geral de Instrucção Publica. Lisboa: Imprensa Nacional, 1877. 
FIGURA 6 - MODELO DE CARTEIRA ESCOLAR PROPOSTO PELA DIREÇÃOGERAL DE INSTRUÇÃO PÚBLICA (1877)

Mesa com bancos separados, para 2 alumnos, com prateleira por baixo da tampa

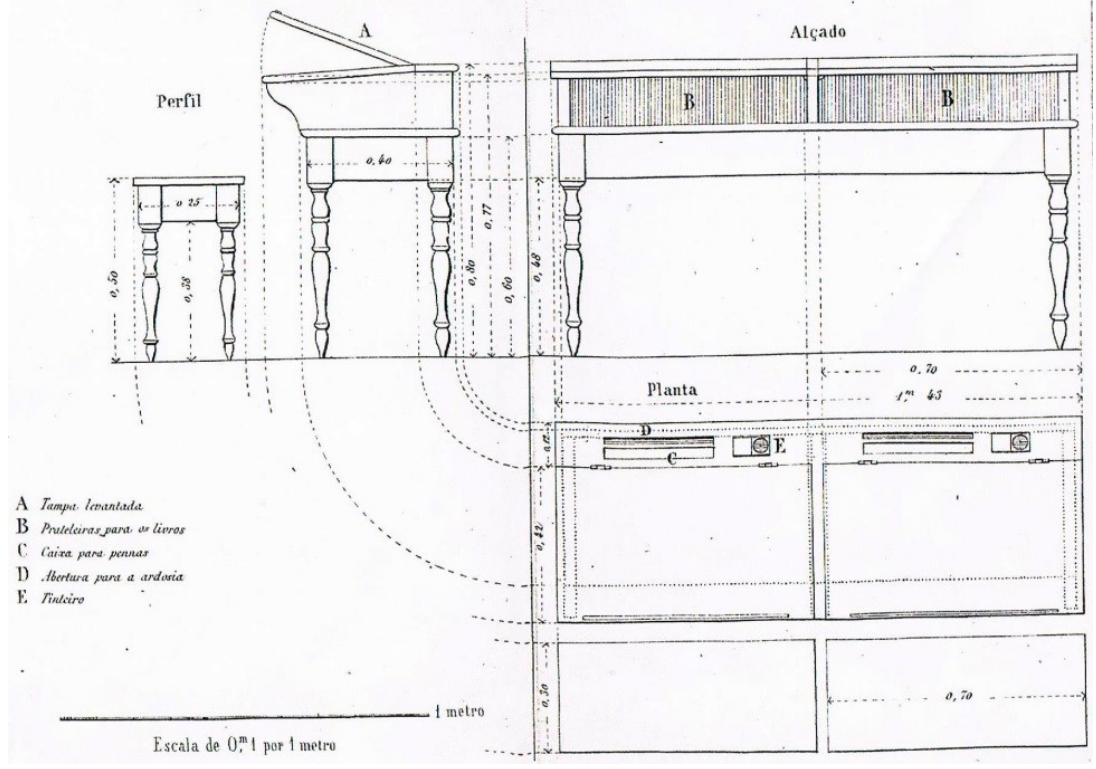

FONTE: Modelos de Mobilia para Instrucção Primaria Organisados pela Direção Geral de Instrucção Publica. Lisboa: Imprensa Nacional, 1877.

Apenas um dos desenhos apresentava ligeiras similitudes (embora distante do ponto de vista técnico) com o modelo de Kunze. Atente-se na próxima figura. 
FIGURA 7 - MODELO DE CARTEIRA ESCOLAR PROPOSTO PELA DIREÇÃOGERAL DE INSTRUÇÃO PÚBLICA (1877)

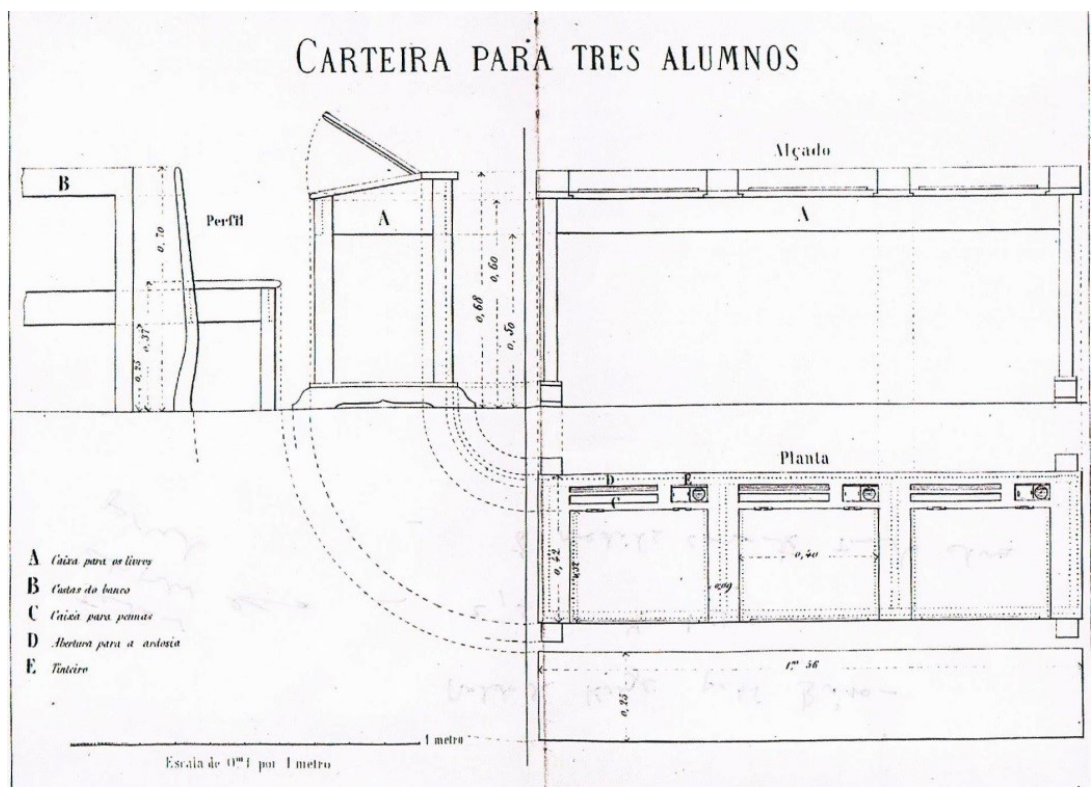

FONTE: Modelos de Mobilia para Instrucção Primaria Organisados pela Direção Geral de Instrucção Publica. Lisboa: Imprensa Nacional, 1877.

A resistência que se observa à classificação e estandardização - na verdade, é disso que se trata - pode ser explicada à seguinte luz. Em primeiro lugar, julgo que têm algum peso/influência as técnicas de carpintaria locais, algo particularmente visível no capítulo da decoração (cf. as Figuras 2, 6 e 8). 
FIGURA 8 - MODELO DE CARTEIRA ESCOLAR PROPOSTO PELA DIREÇÃOGERAL DE INSTRUÇÃO PÚBLICA (1877)

\section{Mobilia da Escola normal. - Carteira e cadeira para um alumno.}

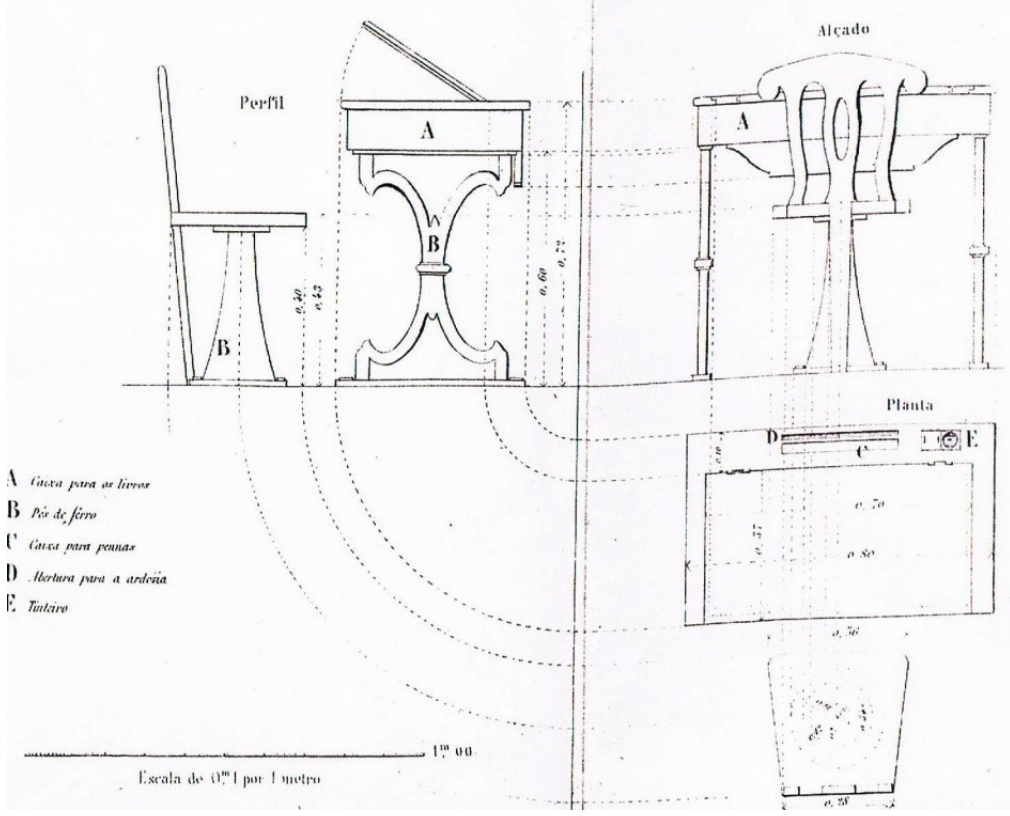

FONTE: Modelos de Mobilia para Instrucção Primaria Organisados pela Direção Geral de Instrucção Publica. Lisboa: Imprensa Nacional, 1877.

Por outro lado, há questões pedagógicas que devem ser consideradas. Por exemplo, na linha do que argumentaram Herman, Van Gorp, Simon \& Depaepe (2011), a opção pelo banco corrido (a lembrar o mobiliário do ensino mútuo) encontra a sua razão de ser no facto de o modelo em causa se ajustar à realidade pedagógica (isto é, provar bem). Efetivamente, em 1877, na quase totalidade das escolas primárias do país não existia nexo entre a hierarquização das classes e a idade dos alunos (o que sucederá mais tarde com a consolidação da escola graduada). Ora, isso pressupunha que as carteiras escolares acomodassem alunos de diferentes estaturas (o que era facilitado, obviamente, com o modelo de banco corrido de vários lugares). Mais, fatores de natureza financeira terão, também, condicionado a proposta emanada da Direção-Geral de Instrução Pública. 


\section{Considerações finais}

A variedade de representações de carteiras escolares que analisei não pode ser apenas vista como parte de um processo de aceitação de modelos globais pelas forças locais. Efetivamente, não obstante a referência ao internacional e o facto de o conhecimento pedagógico circular com integridade (para adotar as palavras de Mary Morgan), o modelo de carteira escolar criado por Kunze, e promovido na Exposição Universal de Viena (1873), serviu, no fundamental, para "legitimar" a proposta emanada da Direção-Geral de Instrução Pública, em 1877. Com efeito, se a nível macro é indiscutível a disseminação e estandardização do conhecimento pedagógico (as exposições universais elucidam-no de forma eloquente), por seu turno, localmente, assiste-se a processos de diversificação cultural. No caso em apreço, verifica-se que é mínima a permeabilidade ao conhecimento veiculado; as razões, entre outras que procurei explicitar, prendem-se com a realidade pedagógica portuguesa desse período histórico. $\mathrm{O}$ que interessava - é essa, aliás, a principal forma de receção - era demonstrar estar ligado ao conhecimento internacional. Por fim, o presente artigo sublinha a importância que a história das materialidades tem na compreensão das práticas escolares; ao mesmo tempo, chama a atenção para a necessidade de utilização de fontes menos estandardizadas.

\section{REFERÊNCIAS}

BUISSON, Ferdinand. Rapport sur l'Instruction Primaire à L'Exposition Universelle de Vienne en 1873. Paris: Imprimerie Nationale, 1875.

CARVALHO, Luís Miguel. Notas para um estudo da circulação e estruturação do conhecimento educacional na imprensa de educação e ensino. In: Ó, Jorge Ramos; CARVALHO, Luís Miguel (ed.). Emergência e Circulação do Conhecimento Psicopedagógico Moderno (1880-1960). Estudos Comparados Portugal-Brasil. Lisboa: Educa e Unidade de I\&D de Ciências da Educação, 2009, p. 173-194.

ESCOLANO BENITO, Agustín. Ethnohistory and Materiality of Education: in the setting of the Universal Exhibitions. In: LAWN, Martin (ed.). Modelling the Future: exhibitions and the materiality of education. Oxford: Symposium Books, 2009, p. 31-49.

FRADESSO DA SILVEIRA, Joaquim Henrique. Notícia da Exposição Universal de Vienna d'Austria em 1873. Bruxelles: Typ. E. Gueyot, 1873. 
FRADESSO DA SILVEIRA, Joaquim Henrique. Relatorio do serviço do comissariado portuguez em Vienna de Austria na Exposição Universal de 1873. Lisboa: Imprensa Nacional, 1874.

HERMAN, Frederik; VAN GORP, Angelo; SIMON, Frank; DEPAEPE, Mark. Sources and interpretations the school desk: from concept to object. History of Education, Journal of the History of Education Society, n. 40 (1), p. 97-117, 2011.

LAWN, Martin (ed.). Modelling the Future: exhibitions and the materiality of education. Oxford: Symposium Books, 2009.

MACHADO, Maria de Fátima de Sá. Maneiras de Sentar. Contributo para a História das Carteiras Escolares do Ensino Primário em Portugal (1835-1970). Lisboa, 2004. Dissertação (Mestrado em Ciências da Educação) - Faculdade de Psicologia e de Ciências da Educação da Universidade de Lisboa, Lisboa, 2004.

Modelos de Mobilia de Instrução Primaria Organisados por Ordem da Direcção Geral de Instrucção Publica. Lisboa: Imprensa Nacional, 1877.

MORGAN, Mary S. Travelling Facts. In: MORGAN, Mary S.; HOLETT, Peter (ed.). How Well do Facts Travel? The dissemination of reliable knowledge. Cambridge: Cambridge University Press, 2011, p. 3-39.

OLSON, Robert J. M.; REILLY, Patricia L.; SHEPHERD, Rupert. The Biography of the Object in Late Medieval and Renaissance Italy. Malden, MA Oxford e Victoria: Blackwell, 2006.

PERES, Isabel Marília; COSTA, Fernanda Madalena; JARDIM, Maria Estela. Fotografia na Meteorologia e Geomagnetismo. In: COSTA, Fernanda Madalena; JARDIM, Maria Estela (coordenação). 100 Anos de Fotografia Cientifica em Portugal (1839-1939). Imagens e Instrumentos. Lisboa: Edições 70, 2014, p. 61-82.

PHILLIPS, David. Toward a Theory of Policy Attraction in Education. In: STEINERKHAMSI, Gita (ed.). The Global Politics of Educational Borrowing and Lending. New York: Teachers College, 2004, p. 54-67.

SILVA, Carlos Manique da. Escolas Belas ou Espaços Sãos? Uma análise histórica sobre a arquitetura escolar portuguesa (1860-1920). Lisboa: Instituto de Inovação Educacional, 2002.

SOUTO, Maria Helena. Portugal nas Exposições Universais (1851-1900). Lisboa: Edições Colibri - IHA/Estudos de Arte Contemporânea, FCSH - Universidade Nova de Lisboa, 2011.

Texto recebido em 10 de maio de 2019.

Texto aprovado em 28 de junho de 2019. 